\title{
EXTENSÃO CURRICULAR VIVENCIADA POR ESTUDANTES DE CIÊNCIAS BIOLÓGICAS EM UMA UNIVERSIDADE DO SUL DE SANTA CATARINA
}

\author{
Maristela Goncalves Giassi ${ }^{1}$ \\ Juliana Medeiros Borghezan² \\ Suelane Cardoso Fenali ${ }^{3}$ \\ Luis Paulo Cezar Nunes ${ }^{4}$
}

\begin{abstract}
RESUMO
A extensão universitária é alvo de muitas discussões e reflexões relacionadas à sua importância e aplicação em uma Universidade. Este artigo tem por objetivo relatar uma experiência de extensão curricular vivenciada por acadêmicos da primeira fase do curso de Ciências Biológicas na disciplina de História e Filosofia da Ciência (HFC). Para tanto, a turma visitou um bairro da cidade impactado pela mineração de carvão, observou e levantou dados com os moradores, com a Prefeitura Municipal e em outras fontes, associando aos conteúdos previamente estudados na referida disciplina. Os resultados indicam a iminente necessidade de educação ambiental dos moradores locais, e a necessária atuação da municipalidade no que tange à questão ambiental. Como ações, foram desenvolvidas atividades educativas com os estudantes da escola daquela comunidade e a apresentação de seminário final na Universidade.
\end{abstract}

Palavras-chave: Ciência, tecnologia e sociedade. Ensino, pesquisa e extensão. Ensino superior. Extensão.

\begin{abstract}
The university extension is the subject of many discussions and reflections related to its importance and application in a University. This article aims to report an experience of curricular extension experienced by academics of the first year of the Biological Sciences course in the discipline of History and Philosophy of Science (HFC). Therefore, the group visited a neighborhood impacted by coal mining, observed and raised data with the residents, with the City Hall and other sources, associated those data to the contents previously studied in the discipline. The results indicate the imminent need of environmental education for the local residents and the necessity of actions from the public managers regarding to the environmental issue. Educational activities were developed with the school students of that community and a workshop at the University.
\end{abstract}

Keywords: Extension. Higher education. Science, Technology and Society. Teaching, research and extension.

\section{Introdução}

A Extensão Universitária ganha cada vez mais espaço dentro das instituições de ensino, fixando-se de forma concreta como um dos grandes tripés - ensino, pesquisa e extensão - dentro das universidades. No entanto, a discussão sobre extensão atualmente extrapola os limites da relação entre esses três princípios, transformando-se em um importante item a ser inserido na formação curricular de acadêmicos e professores com o objetivo de estabelecê-la como uma ponte de interação, compreensão e aplicação dos conteúdos científicos a serviço da sociedade.

\footnotetext{
1 Professora do Curso de Ciências Biológicas da Universidade do Extremo Sul Catarinense (UNESC). Doutora em Educação Científica e Tecnológica pela Universidade Federal de Santa Catarina (UFSC). E-mail: mgi@unesc.net

2 Acadêmica do Curso de Ciências Biológicas da UNESC. E-mail: borghezanj@outlook.com

3 Acadêmica do Curso de Ciências Biológicas da UNESC. E-mail: suelanecfenali@gmail.com

${ }^{4}$ Acadêmico do Curso de Ciências Biológicas da UNESC. E-mail: luispaulo.nunes6@gmail.com
} 
O conceito de extensão é discutido por diversos estudiosos, tendo em vista compreender e estabelecer cada vez mais sua função na educação. Paulo Freire (2013), por exemplo, traz em sua obra “Extensão ou Comunicação?” a reflexão sobre a comunicação humanista e a forma de estender os conhecimentos gerados nas universidades para a sociedade.

Segundo Freire (2013), estender os conhecimentos é necessário e deve acontecer de forma clara e dialógica. Isto é, o conhecimento não se estende daquele que julga saber até aqueles que julgam não saber; na realidade, de acordo com o autor, uma das formas que o conhecimento se constrói e se aperfeiçoa é por meio da problematização, que para acontecer necessita de diálogo. Conforme Freire (2013, p. 51), o diálogo tem papel fundamental na extensão:

E ser dialógico, para o humanismo verdadeiro, não é dizer-se descomprometidamente dialógico; é vivenciar o diálogo. Ser dialógico é não invadir, é não manipular, é não sloganizar. Ser dialógico é empenhar-se na transformação constante da realidade.

Para o autor, as informações não são impostas e simplesmente despejadas para a sociedade. O extensionista precisa ser capaz de compreender a realidade e a cultura em que os indivíduos estão inseridos, valorizar os conhecimentos que já possuem e assim proporcionar uma troca de saberes. Tratando ainda do diálogo, Freire (2013 p. 65) declara que:

O que se pretende com o diálogo, em qualquer hipótese (seja em torno de um conhecimento científico e técnico, seja de um conhecimento "experiencial"), é a problematização do próprio conhecimento em sua indiscutível reação com a realidade concreta na qual se gera e sobre a qual incide, para melhor compreendê-la, explicá-la, transformá-la.

O autor deixa claro que a construção do saber por meio da extensão só é possível quando houver dialogicidade plena, com a contribuição de ambas as partes, frisando a importância de que o extensionista não deve agir como invasor cultural, mas sim respeitar todo o conhecimento já existente naquela comunidade, levando seu conhecimento, como também agregando em si o conhecimento encontrado.

Para o Conselho Universitário da Universidade do Extremo Sul Catarinense (UNESC), estabelecido por meio das Políticas de Extensão (2015, p. 8), a Extensão é entendida como o "processo educativo, cultural e científico que articula o ensino e a pesquisa de forma indissociável e viabiliza a relação transformadora entre a Universidade e a Sociedade".

Diante da premência e discussões derivadas do Plano Nacional de Educação (PNE) (IMPERATORE, J. L. B.; PEDDE; IMPERATORE, S. L. R., 2014), a respeito da curricularização da extensão e sua aplicação em sala de aula, os professores foram instigados a pensar neste processo, o que desencadeou ações extensionistas mais sistematizadas nas Universidades. A partir das reflexões, percebe-se que muita coisa já é realizada, porém outras necessitam ser incrementadas, oportunizando 
maior interação dos conteúdos científicos junto às comunidades de forma prática, contribuindo positivamente para ambas as instituições.

Neste cenário, por imperativo da Lei No 13.005 de 25 de julho de 2014 do Plano Nacional de Educação (PNE), as Instituições de Ensino Superior (IES) estão adequando seus currículos para viabilizar a extensão curricular que exige a implantação de até $10 \%$ da carga horária dos cursos de graduação em atividades de extensão. Com o incremento da extensão na história universitária e a importância dada à curricularização da extensão no espaço acadêmico, amplia-se a percepção do impacto da extensão para a formação de um profissional qualificado. Segundo Jezine (2004, p. 2),

A concepção de extensão como função acadêmica se opõe a ideia de que constitua uma atividade menor na estrutura universitária, a ser realizada por professores sem titulação, nas sobras de tempo disponível e que o trabalho junto às comunidades carentes é uma solidariedade individual. Diante dessa nova visão de extensão universitária, esta passa a se constituir parte integrante da dinâmica pedagógica curricular do processo de formação e produção do conhecimento, envolvendo professores e alunos de forma dialógica, promovendo a alteração da estrutura rígida dos cursos para uma flexibilidade curricular que possibilite a formação crítica.

Para a autora, a inclusão da extensão no currículo universitário é uma ideia que tende a se estabelecer, dada a sua importância para a formação profissional do acadêmico. Corroborando com estas ideias, Dias (2009, p. 24) complementa que "quanto mais integradas estiverem às ações de ensino, pesquisa e de extensão, mais integralmente se estará formando o profissional para o mundo do trabalho do seu século." Para os autores, o contato com a realidade social favorece consideravelmente a articulação entre o ensino a pesquisa e a extensão.

De acordo com Imperatore, S. L. B., Pedde e Imperatore, J. L. R. (2015, p. 2), o reconhecimento da extensão como função acadêmica integrada ao currículo pressupõe,

uma extensão que transpõe suas contradições históricas e polissemia e se reconfigura em programas e projetos para além de um canal de comunicação e legitimação de saberes hegemônicos ou mera prestação de serviços assistencialistas, mas espaço de construção do conhecimento, portanto, processo dialógico, crítico, reflexivo, educativo, científico, interdisciplinar e emancipatório.

Para os autores, a extensão tem a sua função para além da mera formação profissional, ela aponta para as demandas sociais, políticas, econômicas e culturais da sociedade; que pense a formação cidadã, com uma visão ampliada de mundo e de sociedade.

Nessa linha de reflexão, a resolução do Conselho Universitário da UNESC (n. 12/2015/CONSU, p. 38), percebe esse processo como,

A ação permanente de formação em ensino, pesquisa e extensão é uma necessidade nas atividades de uma universidade. Constitui-se em uma ação de reflexão perene sobre a sua prática, um repensar constante no intento de aperfeiçoar a ação realizada. 
Nesse sentido, é importante citar a presença da indissociabilidade entre pesquisa, ensino e extensão, fator relevante que ainda necessita ser melhor compreendido pela comunidade acadêmica. Durante o desenvolvimento desse projeto foi perceptível que esses três suportes de uma universidade são complementares, fazendo maior sentido quando vinculados entre si. Dias (2009, p. 39) reforça dessa relação, destacando que,

A relação entre o ensino, a pesquisa e a extensão, quando bem articulados, conduz a mudanças significativas nos processos de ensino e de aprendizagem, fundamentando didática e pedagogicamente a formação profissional, os estudantes e professores constituem-se, efetivamente, em sujeitos do ato de aprender, de ensinar e de formar profissionais e cidadãos.

O funcionamento conjunto deste tripé universitário proporciona resultados significativos. Possibilita um olhar para a realidade, entendendo o sentido de muitos conteúdos científicos sistematizados e estudados em sala de aula, deixando claro o vínculo que existe entre eles. Esta interação possibilita "operacionalizar a relação entre teoria e prática, a democratização do saber acadêmico e o retorno desse saber à universidade, testado e reelaborado" (DIAS, 2009, p. 39-40).

Assim sendo, no primeiro semestre de 2016, foi realizada com acadêmicos de Ciências Biológicas, uma atividade com o objetivo de vivenciar um processo de extensão curricular na disciplina de História e Filosofia da Ciência em um bairro da região, inserido num espaço denominado pela universidade como "Território Paulo Freire". Este território está incluído em um Programa de Extensão que abrange alguns bairros marcados por questões socioambientais e possui como base os referenciais do autor Paulo Freire - motivo da denominação do programa. Segundo o site da UNESC (2017),

O Programa se torna diferenciado pelo modo como os projetos foram concebidos. Todos retratam as necessidades da comunidade envolvida, tendo em vista que antes da elaboração dos mesmos, grupos de professores e acadêmicos reuniram-se com lideranças comunitárias dos bairros da Grande Santa Luzia (12 bairros aproximadamente) em novembro e dezembro de 2013, apoiados pela UABC (União das Associações de Bairros de Criciúma, SC) para identificar as demandas da população daquela região.

Este tem como principal objetivo o desenvolvimento de projetos que permitam ampliar a autonomia das comunidades. Além disso, "sabe-se que a formação de profissionais competentes envolve diferentes dimensões, dentre elas, o contato com a realidade, aprendendo por meio da ação reflexão - ação", garantindo a ligação entre o ensino, a pesquisa e a extensão na UNESC (UNESC, 2017).

Nesse contexto, este trabalho tem por objetivo relatar uma experiência de extensão curricular vivenciada por acadêmicos da primeira fase do curso de Ciências Biológicas na disciplina de História e Filosofia da Ciência (HFC). 


\section{Procedimentos metodológicos}

Esta atividade foi desenvolvida na disciplina de HFC, com os acadêmicos da primeira fase do curso de graduação - Bacharelado em Ciências Biológicas da UNESC, no primeiro semestre de 2016. Já na apresentação do plano de aula, a professora informou que haveria uma atividade específica na disciplina que envolveria uma ação na comunidade, a fim de colocarem em prática alguns conteúdos e realizar uma vivência ou experiência de extensão curricular.

Inicialmente, os acadêmicos tiveram as aulas com alguns conteúdos, a partir dos quais puderam construir conhecimentos referentes às influências da ciência na história humana, bem como compreender a relação existente entre ciência, tecnologia e sociedade. Os estudos Ciência, Tecnologia e Sociedade (CTS) foram o eixo condutor das análises desenvolvidas pelos estudantes, após a visita ao bairro.

A turma trabalhou em equipes para melhor desenvolver suas atividades, objetivando a busca de informações.

Em um segundo momento, após as devidas reflexões sobre o tema citado acima, realizou-se uma visita ao bairro São Sebastião e São Defende em Criciúma, proporcionando aos alunos o conhecimento da área trabalhada. Nesta saída de estudos, os acadêmicos conversaram com alguns moradores da região, conheceram uma nascente localizada no loteamento Santo André - pertencente ao bairro São Defende e reuniram informações pertinentes para realizar o trabalho acadêmico que foi apresentado na disciplina citada. Posteriormente foi realizada outra visita ao bairro, para realização das entrevistas e aqueles que necessitaram pesquisar em outras fontes, como na prefeitura, no I-Parque (Instituto de Pesquisa da UNESC), no Departamento Nacional de Pesquisa Mineral (DNPM), com outros professores, ou mesmo na Internet, pôde utilizar este dia de aula para isso. Além disso, parte dos alunos voltou ao bairro em outros dias para realizar outras pesquisas e/ou complementar a que havia pesquisado. As idas ao bairro foram com um micro-ônibus, financiadas pelo curso de Ciências Biológicas, locus do curso, da disciplina e dos estudantes.

Cabe aqui lembrar, que esta ação desenvolvida na disciplina, teve um eixo de parceria com o projeto de extensão vinculado ao Território Paulo Freire citado acima, em função do local onde estavam sendo realizados os estudos. Assim, alguns estudantes do curso de Arquitetura também participaram de algumas atividades, pois no projeto atuam em conjunto professores de três cursos: Ciências Biológicas, Arquitetura e Ciências Contábeis.

Os grupos procuraram ter um conhecimento geral do local e cada um deles aprofundou um pouco mais em aspectos como: a história de uma Área de Preservação Permanente (APP) que possui uma nascente; a constituição e história dos bairros trabalhados; a constituição original e atual da flora e a fauna local; a indústria de carvão localizada no bairro; impactos na saúde e na vida resultante do contato diário com este ambiente. Nessas atividades, o objetivo foi possibilitar aos estudantes uma ação 
prático-reflexiva sobre as relações entre a Ciência e Tecnologia na sociedade, e também refletir como sua profissão de biólogo pode ser vinculada à sociedade.

Para isso, utilizaram-se os textos estudados em aula; as visitas ao bairro; as pesquisas em diversas fontes; as entrevistas e o olhar atento sobre o local visitado.

Após a coleta e sistematização das informações, foi realizada uma apresentação nos dois cursos, Arquitetura e Ciências Biológicas. Foram realizadas também, como forma de devolutiva para a comunidade, atividades em forma de oficinas relacionadas aos aspectos pesquisados pelos acadêmicos. Estas aconteceram na escola do bairro, sendo a forma mais prática encontrada de devolutiva dos conhecimentos construídos a partir das atividades realizadas.

Os resultados e as reflexões desencadeadas serviram também para articular entre os cursos uma vivência interdisciplinar, que no entender dos participantes, só não foi melhor, em razão dos horários que estudam, motivo pelo qual, nem todos os colegas puderam comparecer nas oficinas da escola e do curso de Arquitetura. Esta turma pertence ao período noturno, são estudantes trabalhadores, sendo difícil sair durante o dia para atividades extraclasse.

\section{Resultados e discussões}

No que tange aos resultados obtidos, é importante citar a contribuição dos moradores da região em estudo, sendo que grande parte das informações coletadas tiveram como base as entrevistas com os moradores do local. Contudo, alguns dados, especialmente os relacionados com a história do bairro, foram obtidos no site da Prefeitura. Com relação à questão ambiental do bairro, todos os trabalhos mencionaram a nascente localizada no loteamento Santo André (figura 1). Esta se situa em uma Área de Preservação Permanente (APP), que é alvo de grande depredação, decorrente da falta de conhecimento da comunidade do real valor de um recurso dessa natureza presente num bairro. Por serem do curso de Ciências Biológicas, percebe-se que o olhar dos acadêmicos dirigiu-se para esta área, destacando-se dentre outras problemáticas presentes no local.

De acordo com as pesquisas dos acadêmicos, a urbanização do bairro São Defende e região foi proveniente da instalação da mineradora de carvão e também de uma coqueria, que tinha sua produção de Coque remetida para a Companhia Siderúrgica Nacional (CSN). Neste quadro de industrialização, a partir da mineração do carvão, abriram-se as portas para a chegada dos moradores naquela localidade. Assim, com o desenvolvimento da indústria e das comunidades na região, tornou-se visível e crescente a degradação ambiental do local.

O estudo e a observação in loco apontaram duas áreas bem distintas. Uma, mais antiga, com os primeiros moradores, dedicados inicialmente à agricultura, os quais preservam esta parte do bairro, mantendo-a limpa, organizada, com quintais e jardins bem cuidados, calçadas limpas, configurando um paisagismo bonito que enobrece o bairro. Outra, paralela à anterior e mais próxima da nascente, o 
aspecto muda completamente, encontra-se um ambiente poluído, com grande quantidade de lixo e águas paradas nas ruas, indicando a falta de saneamento básico, contrastando fortemente com a primeira parte observada.

A falta de atenção do poder público com as Áreas de Preservação Permanente (APP) possibilitou a abertura de uma estrada rente à nascente nesta área. Com isso, houve um maior crescimento populacional no local. Junto veio também a invasão por moradores provenientes de diversos locais e como consequência direta, invasões e mais depredação do espaço verde - APP, onde se localiza a nascente.

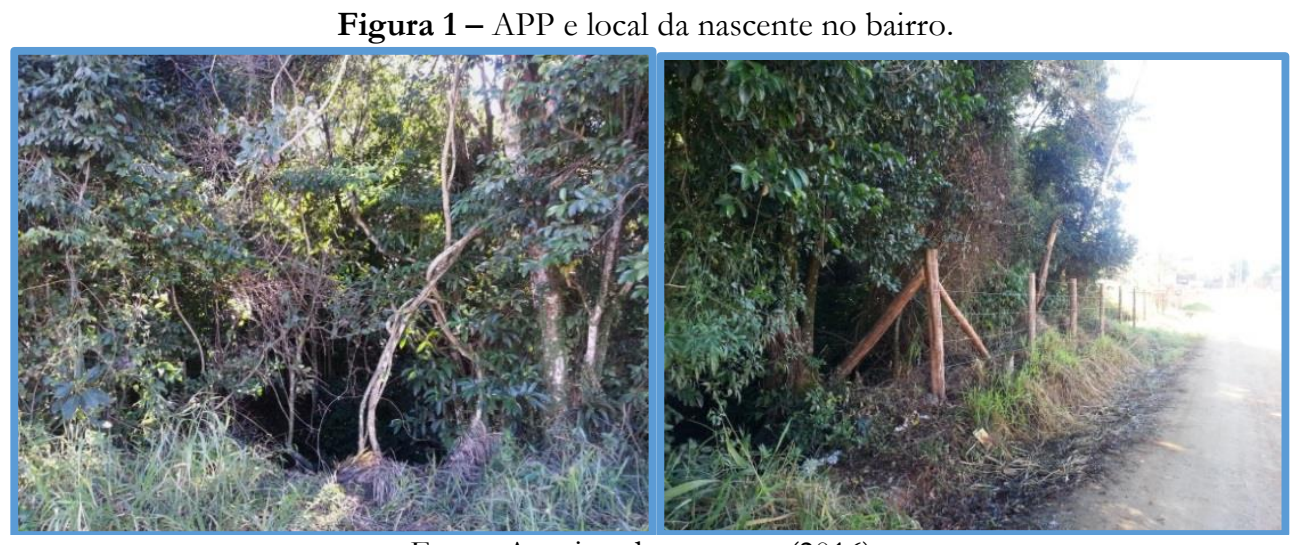

Fonte: Arquivo dos autores (2016).

Segundo o relato dos moradores mais antigos da região, a nascente já foi de extrema importância para o abastecimento da população local até por volta do ano de 1996. Nessa época começaram a surgir as primeiras casas no novo loteamento. Constataram também, que o uso da nascente no cotidiano da população permaneceu até o surgimento do acesso a água da Companhia Catarinense de Águas e Saneamento (CASAN), visto que, com o desenvolvimento do bairro, apenas a nascente não estava mais suprindo a demanda, sendo necessária maior disponibilidade de água tratada. Este seria, de acordo com a comunidade, um dos principais fatores que influenciaram no descuido com a nascente, uma vez que, não necessitavam mais usufruir deste bem natural para a obtenção de água.

Percebe-se também que além da necessidade de mais água potável, o aumento da população que ali chegava contribuiu com a depredação daquele espaço de preservação. Pode-se constatar no estudo que, pelo fato de muitos moradores serem novos no local e não o conhecerem direito, não davam o devido valor ao que tinham próximo de sua casa, não conheciam a história do bairro e sequer sabiam o que era uma APP. Os depoimentos de alguns moradores indicam que embora olhassem para aquela área verde (APP) até com admiração, como grande parte da população que carece de conhecimentos, aquele local passou a ser visto como mais um "terreno baldio" que servia e que ainda serve como descarte para os materiais que ninguém mais queria no seu quintal (figura 2).

Destacou-se também no estudo, o impacto ambiental presente nos bairros, em razão da indústria mineradora. A mineração e a coqueria foram responsáveis por gerar uma grande quantidade 
de rejeitos deixados com a exploração do carvão, que somado às outras mineradoras de carvão, ocasionou a poluição do solo, da água e do ar do município e região, gerando um passivo ambiental que perdura ainda hoje e espera por soluções. Como mencionado por Farias (2002), os rejeitos xistosos e piritosos produzidos nos pré-lavadores foram sendo depositados, durante décadas, próximos aos prélavadores, causando grande impacto ambiental, principalmente em consequência da pirita.

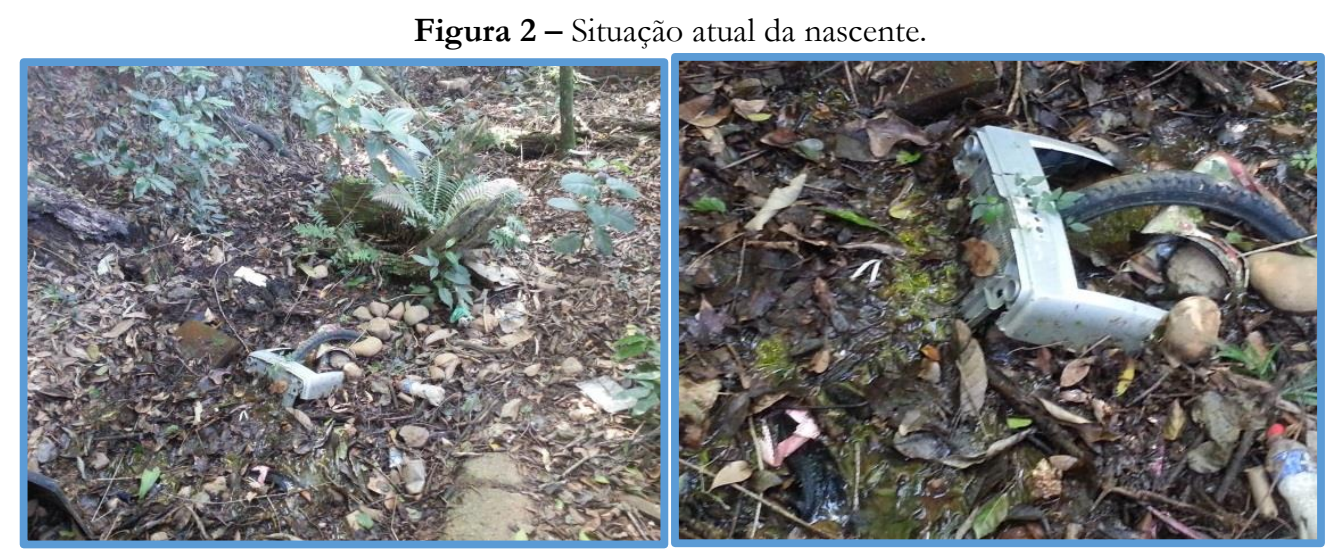

Fonte: Arquivo dos autores, (2016).

Já na imagem abaixo, destacamos um poço de decantação de água da lavação de carvão e um detalhe do processo de recuperação ambiental que foi realizado no local pela mineradora atualmente desativada. Esse processo de recuperação foi realizado por força da lei, que obriga as empresas a fazerem a recuperação das áreas degradadas, porém, ainda não está completa. Observa-se também, claramente que, pela escassez da cobertura colocada, em muitos locais, a chuva já carreou boa parte da terra colocada por cima, deixando novamente à mostra o rejeito piritoso logo abaixo, permitindo que continue o potencial poluidor que ali se encontra (figura 3).

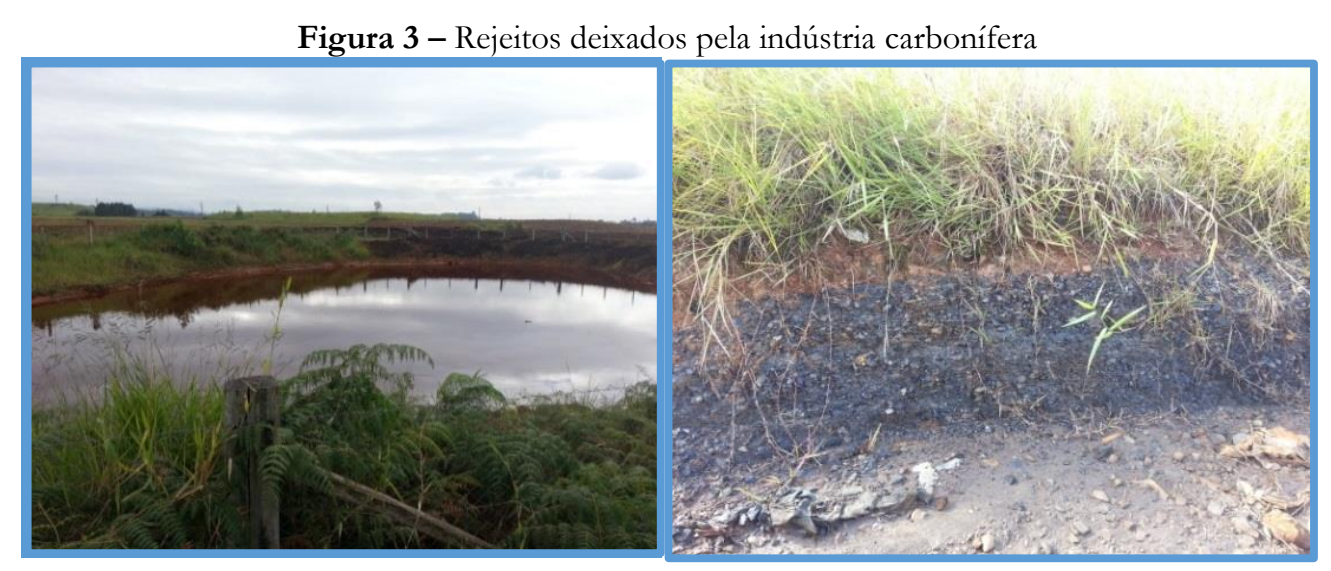

Fonte: Arquivo dos autores (2016).

Com base nessas informações, algumas relações entre a Ciência, Tecnologia e Sociedade (CTS) podem ser descortinadas, pois de acordo com Palacios et al. (2003), os Estudos CTS servem para compreender as relações sociais e consequências socioambientais que decorrem dessa relação, isto é, da relação entre a Ciência, a Tecnologia e a Sociedade. De acordo com os autores, a Visão Clássica da 
relaçao entre C T S é uma concepção essencialista e triunfalista. E esta visão se traduz num "Modelo Linear de Desenvolvimento" $=+$ Ciencias $=+$ Tecnologia $=+$ riqueza $=+$ Bem estar social. "Tal concepção com frequência está presente em diversos espaços do mundo acadêmico e nos meios de divulgação" (PALACIOS et al., 2003, p. 120). Neste tipo de visão, de acordo com os autores, a Ciência e a Tecnologia podem se desvincular da sociedade, porque elas precisam buscar a verdade e, para isso, não deverá ter limites ou interferência para chegar aos seus fins.

No contexto acima, ao olharmos para as mazelas socioambientais encontradas no bairro, a primeira discussão promovida pelos estudantes, foi sobre a produção de conhecimentos. Se o conhecimento levou o ser humano a produzir tecnologias capazes de aliviar nossas tarefas, mas ao mesmo tempo impactar de tal modo um ambiente antes saudável e "natural", qual seria a vantagem de tê-lo à nossa disposição? Nessas reflexões, como mediadora, a professora chamou a atenção de para quem ou para quantos essa tecnologia estava trazendo vantagens? As reflexões caminharam para as empresas mineradoras e seus grandes retornos financeiros; caminharam também para os trabalhadores e seus problemas de saúde; para o bairro que antes fora saudável e possuidor de belas paisagens; para o ambiente que possuía a água, as nascentes e a mata original e produtiva; para os moradores atuais, especialmente os da área mais prejudicada e de invasão, que não conseguiam ver a situação em que se encontravam e começou-se então a perceber como o conhecimento e a ciência poderiam gerar progresso, mas também a divisão, a diferença e estar a favor de uns em detrimento de outros.

O fato de morarem sobre a pirita, ou junto de entulhos de lixo, parecia não ter significado para uma parte dos moradores. Porque havia tanta diferença entre os moradores de uma parte do bairro e, tão próximo, outra tão depredada? Nessas reflexões, os estudantes puderam pensar no acesso ao conhecimento e ao poder aquisitivo de parte da população e refletiram sobre o significado de ser profissional e especialmente no seu caso - um Biólogo! Como deveriam se posicionar? Qual o seu compromisso ético e moral nesses casos? E se trabalhassem em uma mineradora? Como se portariam, por exemplo, agora que por imperativo da lei as áreas mineradas precisam ser recuperadas e sabendo-se das normas técnicas para fazê-lo, poderiam eles permitir que fosse realizada a recuperação que estavam observando no local? Onde o solo já estava sendo carreado e a pirita voltando à tona e continuando com o processo poluidor? Como a própria ciência poderia ajudar nesse sentido? Essas e outras reflexões permearam o processo no seu todo, construindo um desejo dos acadêmicos em dar continuidade com os estudos no local.

Com o reconhecimento que essa ideia de progresso desenfreado promovido pela ciência e pela tecnologia, surgiu de acordo com Palacios et al. (2003), no decorrer de grande necessidade e sofrimento da humanidade, no pós-guerra, os estudantes voltaram a refletir sobre o porquê, após tantos anos da Guerra, ainda se encontra situações tão degradantes, tanto ambiental como social? Suas respostas centraram-se no poder do sistema político e econômico gerido por seres humanos. Quem são os indivíduos que determinam e que ditam os rumos de cidades? Estados? Países? Que profissionais são 
esses que permitem e até incentivam essas atitudes? E nossos empregos? Centrou-se uma discussão na questão de ética profissional, na ciência e também da necessidade de educação ambiental, tanto para os moradores da localidade, quanto para os profissionais que trabalham nessas empresas, já que assim talvez pudessem se posicionar diante de arbitrariedades que tivessem que enfrentar em suas vidas pessoais e profissionais. As discussões chegaram à área de saúde, na qual os próprios trabalhadores das mineradoras precisavam de recursos para os seus problemas de saúde e eles mesmos não podiam usufruir de recursos de altas tecnologias para sua recuperação. Não pelo sistema público de saúde!

Diante disso, passaram a elaborar suas oficinas para trabalhar com os estudantes da escola do bairro. Mesmo sendo turma do bacharelado, a atuação com os estudantes da escola foi primorosa. Cada equipe na sua oficina fez questão de mencionar a nascente, a importância da água, do ar e do solo para a vida. A saúde e a qualidade de vida, a necessidade de manter-se um ambiente de vida limpo e saudável. Trabalharam com as oficinas: $\mathrm{O}$ ciclo da água e sua importância para a vida; O terrário e a fragilidade e harmonia dos ciclos bio, geo químico; A história do bairro e o seu desenvolvimento local; a indústria carbonífera e seus impactos pela cidade. Os cuidados com nosso espaço de vida - o destino correto do seu lixo. Essas ideias também foram discutidas em conjunto com uma turma do curso de Arquitetura que também contribuíram com as oficinas.

Os acadêmicos mostraram-se surpresos com as atitudes dos moradores com relação ao lixo espalhado por todo lodo, no seu terreno e nas ruas, especialmente por afirmarem que é sempre os outros, nunca eles que fazem a ação de sujar. Os estudantes perceberam a premência de uma educação ambiental. Nesse sentido, Guerra e Guimarães (2007) contribuem afirmando existir uma necessidade premente em educação ambiental em todos os graus de escolaridade que perpassa pela universidade, pelas escolas de ensino fundamental e médio, devendo ser refletida pelos educadores, como forma de criar oportunidades para praticá-la, a fim de contribuir para a transformação socioambiental.

O crescimento da indústria do carvão na região foi o principal responsável pela degradação de toda a área, permitindo inferir que o avanço de tecnologias e por consequência da industrialização na região, possibilitasse o crescimento dos bairros, porém, mais em quantidade do que qualidade. Pode-se deduzir ainda, que no âmbito da ciência e tecnologia, o uso e as vantagens deles advindos, ocorreram principalmente por parte das indústrias, claramente com fins lucrativos, contrariamente aos interesses de aspectos naturais e da qualidade do ambiente de vida local. Silva e Ferreira (2015, p. 13) discutem os impactos da mineração sobre o ambiente de vida observando que:

O impacto sócio ambiental envolve desde a geração de emprego e renda, bem como desenvolvimento urbano. A exploração fez com que algumas famílias deixassem suas terras para dar lugar à extração do carvão. Com a forte redução no uso de mão de obra na atividade mineira, muitas familias acabaram ocupando áreas de risco geradas pela mineração do carvão. 
Nesse universo, os resultados obtidos neste trabalho foram levados à comunidade e discutidos na escola do bairro por meio de rodas de conversas e das oficinas, procurando construir uma sensibilização para o cuidado e respeito com o seu ambiente de vida. Freire (2005) acrescenta que precisamos lembrar a capacidade que temos de interferir no mundo. $O$ autor destaca a importância do ato de ensinar para que todos consigam superar as dificuldades e contradições em que vivem, especialmente aqueles das classes menos favorecidas. E, nesse sentido, para Freire (2005, p. 83), a educação problematizadora, comprometida com a libertação, "se funda na criatividade e estimula a reflexão e a ação verdadeiras dos homens sobre a realidade, responde a sua vocação, como seres que não podem autenticar-se fora da busca e da transformação criadora”. Para o autor, a problematização se faz por meio do diálogo, e para que ela aconteça, é necessária a análise crítica e reflexiva dos sujeitos sobre uma dimensão significativa da realidade concreta. Para o autor, o conhecimento pode elevar o grau de consciência das pessoas, possibilitando a mudança necessária para o seu empoderamento e busca de seus direitos.

Os resultados também foram apresentados na universidade, discutidos em sala de aula na disciplina responsável pelo projeto e também no curso de Arquitetura, gerando maior interação entre os cursos (Ciências Biológicas e Arquitetura), envolvendo outros projetos de pesquisa e extensão, também desenvolvidos na região estudada.

\section{Conclusões}

Participar de um projeto de extensão em sala de aula foi uma grande oportunidade de aprendizado tanto para os acadêmicos quanto para professores e comunidade. Poder vivenciar uma experiência de extensão curricular, além de promover a aprendizagem, contribuiu para que os acadêmicos percebessem de perto a realidade de um dos bairros da cidade que é fortemente marcada pela mineração do carvão.

Contribuiu também para perceber a forma como a sociedade manipula o meio onde vive, os seus propósitos, a influência da ciência e os seus resultados muitas vezes irreversíveis. No depoimento dos estudantes, a ação foi mais educativa que os textos lidos neste sentido. Possibilitou ainda, para que a turma da disciplina de História e Filosofia da Ciência conhecesse uma das formas de praticar a extensão universitária, construindo a partir de seu olhar para o mundo, uma leitura possível (pois podem ser construídas outras) da ciência e da tecnologia em sua relação com a sociedade.

Com base nos autores estudados, pode-se atribuir à extensão curricular os benefícios de uma interação direta entre alunos e a comunidade, colaborando para a sua vida acadêmica e garantindo a formação de um profissional mais qualificado. Nesse sentido, torna-se válido propiciar e incentivar a prática de extensão curricular, integrando os alunos ao contexto de sua formação acadêmico 
profissional, por meio de práticas extensionistas, que necessariamente carregam consigo, o ensino e a pesquisa, ampliando o mundo profissional de cada estudante universitário.

\section{Referências}

DIAS, A. M. I. Discutindo caminhos para a indissociabilidade entre ensino, pesquisa e extensão. Revista Brasileira de Docência, Ensino e Pesquisa em Educaşão Física, Cristalina, v. 1, n. 1, p. 37-52, ago. 2009.

FARIAS, C. E. G. Mineração e Meio Ambiente no Brasil. Relatório preparado para o CGEE. 2002.

Disponível em: <http://www.mma.gov.br/estruturas/sqa_pnla/_arquivos/minera.pdf>. Acesso em: 12 jul. 2017.

FREIRE, P. Extensão ou comunicaşão? 8. ed. Rio de Janeiro: Paz e Terra, 2013. . Pedagogia do oprimido. Rio de Janeiro: Paz e Terra, 2005.

GUERRA, A. F. S.; GUIMARÃES, M. Educação ambiental no contexto escolar: questões levantadas no GDP. Pesquisa em Educação Ambiental, São Carlos, v. 2, n. 1, p. 155-166, 2007.

IMPERATORE, S. L. B.; PEDDE, V.; IMPERATORE, J. L. R. Curricularizar a extensão ou extensionalisar o currículo? Aportes teóricos e práticas de integração curricular da extensão ante a estratégia 12.7 do PNE. Repositório Institucional UFSC. Florianópolis, 2015. Disponível em: <https://repositorio.ufsc.br/handle/123456789/136064>. Acesso em: 24 out. 2016.

JEZINE, E. As práticas curriculares e a extensão universitária. In: CONGRESSO BRASILEIRO DE EXTENSÃO UNIVERSITÁRIA, 2., 2004, Belo Horizonte. Anais... Belo Horizonte, 2004. Área Temática de Gestão da Extensão.

PALACIOS, E. M. G. et al. Cadernos de Ibero - América. INTRODUÇÃO AOS ESTUDOS CTS (Ciência, Tecnologia e Sociedade). Organização dos Estados Ibero Ámericanos para a Educação, a Ciência e a Cultura (OEI), 2003.

SILVA, L. M.; FERREIRA, R. L. Impacto ambiental pela mineração de carvão no Sul de Santa Catarina. Caderno Meio Ambiente e Sustentabilidade, v. 6, n. 4, 2015.

UNIVERSIDADE DO EXTREMO SUL CATARINENSE (UNESC). Território Paulo Freire - um elo entre a comunidade e a universidade. Disponível em:

<http://www.unesc.net/portal/capa/index/455/7724>. Acesso em: 12 jul. 2017. 